\title{
A Study on the Impact of COVID-19 Pandemic in African Universities
}

\author{
Elijah Isanda Omwenga \\ University of Kabianga \\ Kericho, Kenya
}

\author{
Peter M. F. Mbithi \\ University of Nairobi \\ Nairobi, Kenya \\ John Mwarabu Chone \\ University of Kabianga \\ Kericho, Kenya
}

\author{
John N. Muthama \\ University of Nairobi \\ Nairobi, Kenya
}

\begin{abstract}
This paper presents a study on how University students, lecturers, administrators and managers perceive the impacts of the of COVID-19 crisis on various aspects of University teaching and learning in Africa, and particularly in Kenya. The sudden closure of campuses as a preventive measure to community transmission shifted face-to-face classes to virtual learning modes. With a sample of 1,236 University students and staff from 18 universities in Kenya and Nigeria, the study reveals that amid the worldwide lockdown and transition to online learning, expectation by $44 \%$ of the students were met. Students were mainly concerned about issues to do with internet connectivity, computing devices and electrical power. In addition, utilising e-Learning tools and platforms for effective student engagement posed limitations of accessibility and affordability for many students. The teaching staff on the other hand were mainly concerned with access to the teaching resources, conducting online teaching, capacity to handle the online mode of teaching, devices and eContent development. The pandemic has exposed the shortcomings of the current higher education system and the need for enhanced policy formulation and implementation on digital infrastructure to adapt to the rapidly changing education ecosystem of the world. In the post-pandemic situation, the use of eLearning and virtual education may become an integral part of the higher education system. Key factors influencing students' satisfaction with the role of their University are also identified as internet access, quality of e-content and e-content development. Policymakers, stakeholders and higher education institutions in Africa may benefit from these findings while formulating policy recommendations and strategies to support University teaching and learning during this and any future pandemics. Universities need to plan the post-pandemic education and research strategies to ensure student learning outcomes and standards of educational quality.
\end{abstract}

Keywords: online; teaching; learning; eLearning; equity; quality; COVID-19; impact

\section{INTRODUCTION}

Coronavirus disease-2019 (COVID-19), a highly transmittable and pathogenic viral infection caused by the severe acute respiratory syndrome coronavirus 2 (SARS-CoV-2), is a rapidly spreading pandemic. The coronavirus disease 2019 (COVID-19) outbreak continues to evolve in the African continent since it was first detected in Algeria on 25 February 2020 (Marelli et al., 2021). As of May 2021, Africa had a total number of 51,000 confirmed cases.

The COVID-19 pandemic has already cost African universities substantial but yet undocumented amount of money. It has cost UK, US and Australian universities an estimated $£ 790$ million, US\$ 14.6 billion and AUS\$ 3.8 billion, respectively. The shutdown has meant that the higher education sector has suffered loss as regards to accommodation, catering, and conference income (Aristovnik et al., 2020; Selvi \& Veilatchi, 2021).

Universities worldwide, including those in Africa, have had to quickly scale up online teaching, with concomitant unexpected expenditure. They have had to fund for staff salaries and research projects. Yet, sizeable as the losses are for the current 2020/2021 academic year, they could easily be dwarfed by those expected next year. The economic downturn will force thousands of youngsters to defer entering University. More than 50 million Africans lost their jobs in April 2020 alone. Prospective students might also be put off by the physical distancing requirements that are likely to prevail on University campuses for the foreseeable future. Much will depend on the dynamics of the pandemic.
The shift to online learning looks set to continue at least until the advent of a successful vaccine for COVID-19. Three key issues of importance, in the context of Kenya's vision 2030, Africa's Agenda 2063 and SDG 4, include: Affordable higher education; Increased access to higher education; and Quality education. The disruptive nature of COVID-19 pandemic has a possible significant threat to these three issues.

This research therefore investigated the impact of COVID19 on University teaching and Learning. In all the institutions where the research was conducted, measures were taken to prevent COVID 19 infections during the beginning of the pandemic. Thus, face-to-face courses were suspended, and then the blended learning of digital and classroom teaching was largely adopted. The laboratories took place in small groups in face-to-face mode while keeping the social distance. Some examinations were conducted face-to-face in small groups, respecting prevention measures; others were conducted virtually. This study attempted to answer questions such as:

(a) How does quality of- and access to- University education relate to online teaching in the crisis conditions?

(b) Are there different opinions among students, faculty and senior management regarding the advantages and disadvantages of online learning?

\section{MATERIALS AND METHODS}

This section describes the study participants and procedure, measures and sampling, data analysis approach and the ethical considerations made. 


\subsection{Study Participants and Procedure}

The target population comprised University students who were at least 18 years old, lecturers, administrators, and managers. The respondents in the target populations were recruited by convenience sampling facilitated by advertising on University communication systems. The online

questionnaire was designed in English. The web-based survey was launched via the open-source web application on 14 June 2021 and remained open until 2 July 2021.

\subsection{Measures and Sampling}

The data was obtained through a web-based comprehensive questionnaire composed of ten (10) mainly closed-ended questions, covering socio-demographic, and other characteristics as well as various components of University education, such as cost of teaching learning, quality of econtent, access to internet, quality of curriculum implementation, the roles and measures of institutions, as well as personal reflections on COVID-19. The questionnaire was divided into three broad sections. The first section comprised three (3) questions on the socio-demographic and academic characteristics of the students, e.g., country and institution of study, level and field of study, citizenship, age, and gender. The second section asked students about the implementation of curriculum in their respective universities, as well as their own performance and expectations. This was followed by a segment covering the infrastructure and skills for studying from home, including one open ended question on what needs to be done differently.

The theoretical approach of the study was implicit, using the transformative learning theory. There was the qualitative part characterized by open ended items in the questionnaire. The quantitative part of the survey constituted the other component. Assessment of the online teaching-learning processes were done through the qualitative methods, while the online teaching-learning outcomes were assessed by quantitative methods (Popa et al., 2020; Zhu \& Liu, 2020).

Purposive sampling was employed. A total of 1,236 responses from 18 universities from Kenya and Nigeria were obtained during the study period spanning June to July 2021. In addition, a survey was conducted in June 2021, targeting Open Distance and electronic Learning (ODeL) and ICT Directors of the eleven (11) universities participating. Exploratory research design was therefore adopted.

\subsection{Data Analysis}

The data preparation, aggregation, and cleaning process were performed in MS-Excel. We report the students' gender, citizenship, status, field of study, quality of e-content, cost of teaching and learning, policy issues, and what need to be done differently.

To test statistical hypotheses, Excel was used. The results of descriptive and testing the hypotheses are reported as follows:

(a) Information on students, lecturers, administrators and managers reported the highest mean value of the analysed aspect; the range (difference between the highest and the lowest mean across all groups); and the significance of the differences.

(b) To analyse which factors influence student satisfaction with the role of their University, descriptive statistical analysis was conducted.

\subsection{Ethical Considerations}

All participants were informed about the details of the study. Study participation was anonymous and voluntary, and respondents could withdraw from the study without any consequences. For data-protection reasons, the online survey was open to people aged 18 or over and enrolled in a higher education institution. Only the researchers had access to the research data. The procedures of this study complied with the provisions of the Declaration of Helsinki regarding research on human participants. The National Commission for Science and Technology (NACOSTI) approved this study, through license no. NACOSTI/P/21/11161. NACOSTI is the body charged with the responsibility of regulating research and Quality Assurance in the Science, Technology and Innovation sector in Kenya.

\section{RESULTS}

The listing of institutions represented in the study population are shown in Table 1 below. Majority of the sample of 1,236 were Kenyan respondents with $10 \%$ of them being from private universities.

\begin{tabular}{|l|l|l|}
\hline University & Count & $\begin{array}{l}\text { \% of Total } \\
\text { Respondents }\end{array}$ \\
\hline Chuka University & 1 & 0.1 \\
\hline Daystar University Kimathi University of & 106 & 8.6 \\
\hline $\begin{array}{l}\text { Dedan } \\
\text { Technology }\end{array}$ & 35 & 2.8 \\
\hline Garissa University & 26 & 2.1 \\
\hline Gretsa Universtiy & 1 & 0.1 \\
\hline Inoorero University & 1 & 0.1 \\
\hline Jomo Kenyatta University of Agriculture & 277 & 22.4 \\
\hline and Technology & 406 & 32.8 \\
\hline Kenyatta University & 17 & 1.4 \\
\hline Kibabii University & 1 & 0.1 \\
\hline Kisii University & 17 & 1.4 \\
\hline Pwani University & 48 & 3.9 \\
\hline South Eastern Kenya University & 1 & 0.1 \\
\hline Technical University of Mombasa & 3 & 0.2 \\
\hline United States International University & 1 & 0.1 \\
\hline University of Ibadan & 80 & 6.5 \\
\hline University of Kabianga & 212 & 17.2 \\
\hline University of Nairobi & 2 & 0.2 \\
\hline Zetech University & $\mathbf{1 2 3 6}$ & $\mathbf{1 0 0}$ \\
\hline Grand Total & & \\
\hline
\end{tabular}

On the other hand, Figure 3.1 below indicates that students constituted the majority of the respondents comprising $67 \%$ followed by Lecturers $19.6 \%$, Administrators $9.5 \%$ and lastly Management comprising $2.9 \%$ of the total respondents. This represented the study population well given that students are the majority of any given University community. 


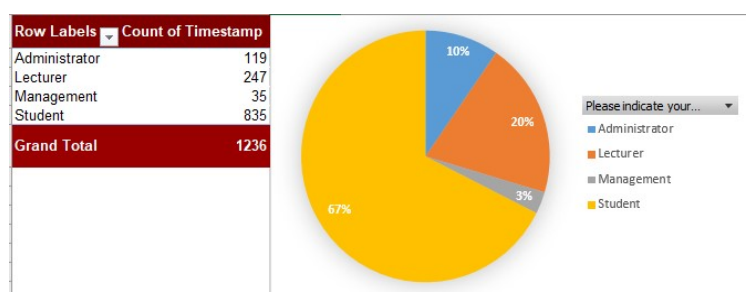

Figure 3.1. Demographic characteristics of participants

It is important to note that the study paid special attention to some eleven (11) Universities that are in a consortium that is participating in a pipeline project seeking support for online learning and requisite infrastructure. These are; Kenyatta University (KU), Daystar University, University of Kabianga (UOK), University of Nairobi (UON), Jomo Kenyatta University of Science and Technology (JKUAT), South Eastern Kenya University (SEKU), Zetech University, Kibabii University, Pwani University, Dedan Kimathi (DeKUT) and Garissa University. Of these Daystar and Zetech are private Universities in Kenya. That is the reason the number of respondents from these Kenyan Universities was relatively higher compared to the rest.

\subsection{Overview of the Questionnaire Results}

The results of the continental survey includes findings concerning different aspects of teaching and learning such as quality, access and affordability of University education (Aristovnik et al., 2020).

\subsection{Quality issues}

Universities around the world, Africa included, cancelled their face-to-face classes and shifted their teaching and learning processes, and some research activities, to online media. For some Universities the online mode of teaching was not new, unlike others who were encountering the mode for the first time. The transition was sudden with inadequate lead time for adequate planning, given that the quality of teaching and learning in these new circumstances needs proper attention (Zhu \& Liu, 2020). On the other hand, students from marginalized and remote areas had problems with poor Internet connectivity or even lack of electricity. Further, poverty was also a factor, leading to a negative attitude towards the online mode (Shenoy et al., 2020). Nevertheless, $49.7 \%$ the students were satisfied with the quality of curriculum implementation (Figure 3.2).
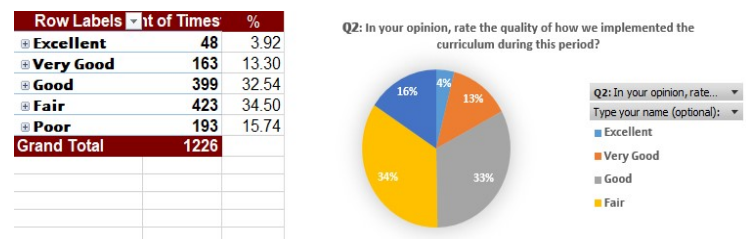

Figure 3.2. Rating of quality of curriculum implementation

The effectiveness of online learning depends on the designed and prepared learning materials, the lecturer's engagement in the online environment, and lecturer-student or studentstudent interactions (Rashid \& Yadav, 2020; Zhu \& Liu, 2020). Further, while studying online from home, students must have an opportunity to ask questions and expect timely answers. Therefore, in the context of quality of education, students were asked about the quality of the content provided online. The students agreed that the quality of e-content was important (Figure 3.3).

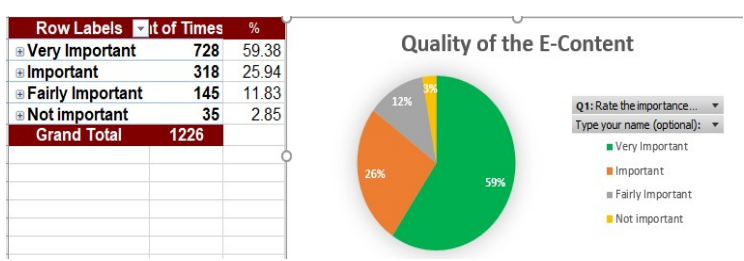

Figure 3.3. Extent to which students' expectations were met

About $44 \%$ of the student respondents indicated that their expectations were met (Figure 3.3). This is a pointer to the need for concerted efforts to ensure that the identified issues by students, for improved performance, are addressed.

Virtual labs and studios constituted an important issue of interest. Results from a survey conducted in June 2021, targeting ODeL directors and ICT directors of the eleven (11) universities participating in the pipeline project, revealed that the Kenya Education Network (KENET) is the main internet service provider. Surprisingly, only $18.8 \%$ of the institutions had virtual (simulation-based) labs. Internet problems, lack of training and difficulty in following instructions emerged as the major issues in using virtual and remote labs. Remote teaching classrooms and studios were almost non-existent $(6.7 \%)$ in the participating institutions with Wacom and Digitizer tablets the most common multimedia authoring tools. A majority of these institutions (73.3\%) do not have infrastructures for differently-abled learners.

\subsection{Access and Affordability issues}

Analysis of data on students' admission and registration revealed a decreasing trend in Admission and Registration of freshmen and women in the period 2018-2020 (see Figure 3.4 below). However, despite their registration, COVID-19 greatly affected curriculum delivery due to disrupted student progression. Therefore, access is declining. The gains which have been made over the years are threatened to be eroded by the COVID-19 pandemic.

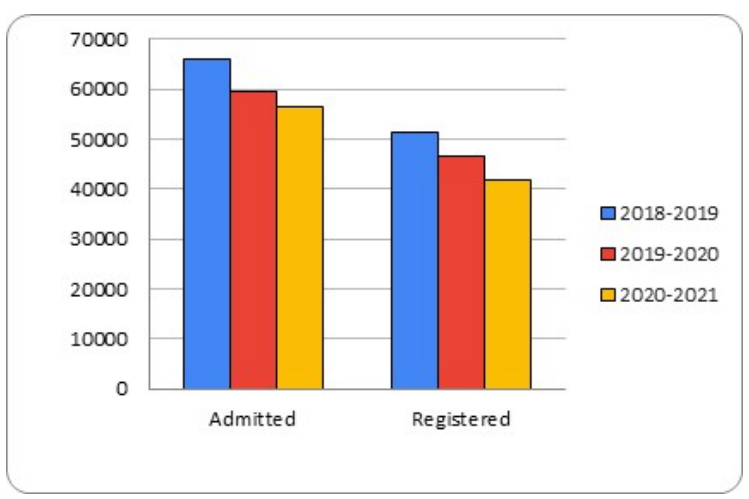

Figure 3.4. Trends on students' admission and registration

Analysis of an open-ended question on what needs to be done differently revealed that over half of the respondents, based on commonly used words from this question, indicated that they have issues with internet access (Figure 3.5). 


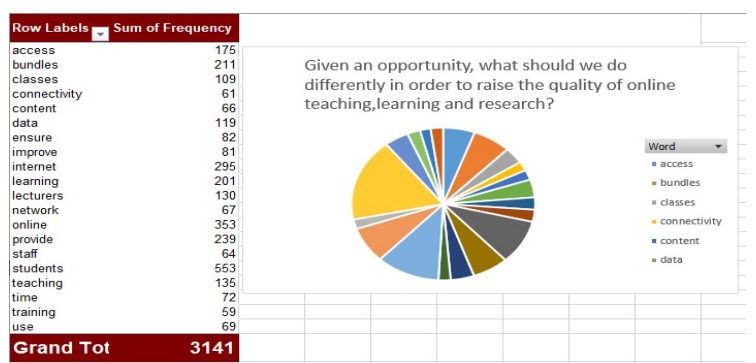

Figure 3.5. The future outlook

Words mentioned that essentially mean the same issue of Internet Access include access, bundles, classes attendance, connectivity, content and data as shown in Figure 3.5 above.

\section{DISCUSSION}

While the world, Africa included, was facing up to the outbreak of COVID-19 pandemic, higher education institutions were crucially affected at their core: the students. For them, the period was undoubtedly unprecedented and very stressful as onsite classes were moved online, semesters were postponed and examinations adjusted, among other measures. Accordingly, there is an urgent need for in-depth studies on how the pandemic crisis has impacted students' lives around the world. The paper by Aristovnik et al., 2020 was the first large-scale global survey among students from different study perspectives since the COVID-19 outbreak. The current study provides premier insights about the impacts of COVID-19 on teaching and learning in Africa, and Kenya in particular. There is need to improve the quality, access and affordability of online teaching and learning in African Universities. This is in agreement with the study by Aristovnik et. al., 2020, conducted between 5 May and 15 June 2020. An attempt was made to illustrate what student life looked like during the COVID-19 pandemic from academic, social, emotional, financial, and other perspectives. In this respect, a number of insights into student life during the lockdown period were observed. First, the students' academic work and academic life aspects were studied. Due to the physical closure of higher education institutions, the majority of teaching and learning processes went online, that is, $86.7 \%$ of all respondents claimed that their onsite classes had been cancelled and substituted with online lectures in the form of real-time video conferences, sending presentations to students, video recordings, and written communication in terms of forums and chats. The students were the most satisfied with real-time video conferences, video recordings, and written communication, with Oceania and Europe emerging as global frontrunners while developing countries, from Asia and Africa, significantly lagged behind (Aristovnik et al., 2020).

\section{CONCLUSION}

Quality of curriculum implementation is such that 55\% success was achieved in online teaching and learning. There is need for the issues that were expressed by $45 \%$ of respondents to be addressed.

Most important issues in e-learning have been identified to be Internet access including devices and electrical power; Quality of e-content; E-content development and Capacity Building .

Implementation challenges faced by universities in Kenya are characterized by institutional, individual and national issues. Central to this is the need for Infrastructural strengthening. In addition, there is a need for policy formulation to address the digital learning in Kenya.

The following are the key recommendations from this study:

(a) Need for adequate support for eLearning infrastructure development for continued delivery of the curricula.

(b) Providing subsidized data bundles and devices to students to maintain/improve access to Internet for learning purposes.

(c) Support to mount virtual labs and studios.

(d) Developing policies, guidelines and processes on eLearning for effective implementation of the teaching programs using technology.

(e) Refocused planning and training by Universities on eLearning for both staff and students.

\section{ACKNOWLEDGMENTS}

This work was done under the auspices of Education for Sustainable Development in Africa (ESDA) phase 2 project suported by the African Development Bank (AfDB). We thank these institutions for their pivotal role in this study. A number of Universities and colleagues also played a part and we are indebted to them. We thank the eleven participating Universities in the consortium and their representatives in the project. These representatives coordinated the data collection exercise and we single them out, with much gratitude, within their respective Universities. For Daystar University we had Dr. Caroline Ayuya, Mr. Samson Mburu and Dr. Sylvia Tuikong; Dedan Kimathi University of Technology: Prof. G K Muthakia, Dr. John M. Wandeto, Mr. Muchiri Michael Njoki and Dr. Moses Ollengo, Garissa University: Dr. Aden Ali Abdi and Mr. Felix Wasike, Jomo Kenyatta University of Agriculture and Technology: Prof. Urbanus N. Mutwiwa, Prof Rebecca W. Waihenya, Prof. Stephen Kimani and Dr. Kipchumba Cherono, Kenyatta University: Dr John Muriuki and Anthony Mbaabu, Kibabii University: Dr. John Wanjala Makokha, Dr. Anselemo Peters Ikoha, Dr. Alice Nambiro Wechuli, Prof. Samwel Mungai Mbugua, Dr. Ben Nyongesa Wekesa, Pwani University: Dr. Leornard Kiti Alii, Dr. Fred Namasaka and Dr. Rose Kigathi, South Eastern Kenya University: Dr. Andrew Omala, Kim Musyoka Musila and Dr. David Musembi, University of Kabianga: Dr. Patrick Bii and Mr. Geoffrey Sowek, University of Nairobi: Prof. Christopher Gakuu and Mr. Paul Kariuki and Zetech University: Dr. Alice Njuguna, Dr. Catherine Njoki and Cyrus Baraza.

\section{REFERENCES}

[1] Aristovnik, A., Keržič, D., Ravšelj, D., Tomaževič, N., \& Umek, L. 2020. Impacts of the COVID-19 Pandemic on Life of Higher Education Students: A Global Perspective. Sustainability 2020, 12(20), 8438; https://doi.org/10.3390/su12208438.

[2] Marelli, S., Castelnuovo, A., Somma, A., Castronovo, V., Mombelli, S., Bottoni, D., Leitner, C., Fossati, A., \& Ferini-Strambi, L. 2021. Impact of COVID-19 lockdown on sleep quality in University students and administration staff. Journal of Neurology, 268(1), 8-15. https://doi.org/10.1007/s00415-020-10056-6

[3] Popa, D., Repanovici, A., Lupu, D., Norel, M., \& Coman, C. 2020. Using Mixed Methods to Understand Teaching and Learning in COVID 19 Times. $\begin{array}{lrrr}\text { Sustainability } & 2020, & 12(20), & 8726 .\end{array}$ https://doi.org/10.3390/su12208726 
International Journal of Computer Applications Technology and Research

Volume 10-Issue 08, 208-212, 2021, ISSN:-2319-8656

[4] Rashid, S., and Yadav, S. S. 2020. "Impact of Covid-19 Pandemic on Higher Education and Research". Indian Journal of Human Development. 14(2): 340-343. https://doi.org/10.1177/0973703020946700

[5] Selvi, D. V. D., \& Veilatchi, K. (2021). "Economic Impact of COVID-19." BSSS Journal of Commerce. XIII(1), 15

[6] Shenoy, Veena, Sheetal Mahendra and Navita Vijay. APRIL, 2020. "COVID 19 - Lockdown: Technology
Adaption, Teaching, Learning, Students Engagement and Faculty Experience". Mukt Shabd Journal. IX(IV). ISSN NO : 2347-3150

[7] Zhu, X., and Liu, J. 2020. "Education in and After Covid-19: Immediate Responses and Long-Term Visions". Postdigital Science and Education, 2(3), 695699. https://doi.org/10.1007/s42438-020-00126-3 